\title{
KARAKTERISASI GRAF POHON DENGAN BILANGAN KROMATIK LOKASI 3
}

\author{
FAIZAH, NARWEN \\ Program Studi Matematika, \\ Fakultas Matematika dan Ilmu Pengetahuan Alam, Universitas Andalas, \\ Kampus UNAND Limau Manis Padang, Indonesia, \\ email : faizahbusyra@gmail.com
}

\begin{abstract}
Abstrak. Misalkan $c$ adalah pewarnaan dengan $k$-warna terhadap suatu graf terhubung $G$. Misalkan $\Pi=\left\{S_{1}, S_{2}, \cdots, S_{k}\right\}$ adalah partisi himpunan $V(G)$ terhadap pewarnaan $c$, dimana $S_{i}$ adalah kelas partisi yang memuat semua titik dengan warna $i$. Kode warna titik $v$, dinotasikan $c_{\Pi}(v)$, adalah vektor dengan panjang $k$ :

$$
c_{\Pi}(v)=\left(d\left(v, S_{1}\right), d\left(v, S_{2}\right), \cdots, d\left(v, S_{k}\right)\right),
$$

dimana $d\left(v, S_{i}\right)=\min \left\{d(v, x) \mid x \in S_{i}\right\}$, untuk $1 \leq i \leq k$. Jika semua titik pada $G$ memiliki kode warna yang berbeda, maka $c$ disebut pewarnaan lokasi pada $G$. Bilangan kromatik lokasi pada $G$, dinotasikan $\chi_{L}(G)$, adalah bilangan $k$ terkecil sedemikian sehingga $G$ memiliki pewarnaan lokasi dengan $k$-warna. Pada tulisan ini dibahas kembali makalah [2] tentang karakterisasi graf pohon dengan bilangan kromatik lokasi 3.
\end{abstract}

Kata Kunci: Pewarnaan lokasi, bilangan kromatik lokasi, graf pohon

\section{Pendahuluan}

Konsep bilangan kromatik lokasi merupakan pengembangan dari konsep dimensi partisi dan pewarnaan graf [4]. Misal terdapat graf $G=(V, E)$. Suatu pewarnaan titik (vertex coloring) dengan $k$-warna adalah suatu pemetaan $c: V \rightarrow \mathbb{N}$ sedemikian sehingga $c(v) \neq c(w)$, jika $v$ dan $w$ bertetangga. Bilangan kromatik (chromatic number) pada $G$ adalah bilangan asli terkecil $k$ sedemikian sehingga jika titik-titik di $G$ diwarnai dengan $k$ warna, maka setiap dua titik yang bertetangga tidak akan mempunyai warna yang sama. Bilangan kromatik pada $G$ dinotasikan dengan $\chi(G)$. Misalkan $\chi(G)=n$, maka pewarnaan titik di $G$ paling sedikit diwarnai oleh $n$ warna.

Misalkan $c$ sebuah pewarnaan titik pada graf terhubung $G$ dengan menggunakan warna-warna $1,2, \cdots, k$ untuk bilangan bulat positif $k$. Jika titik $u$ dan $v$ bertetangga di $G$, maka $c(u) \neq c(v)$. Misal terdapat $S_{i} \subseteq V$ dengan $S_{i}$ adalah himpunan titik di $G$ yang berwarna $i$, maka jarak antara titik $v$ dan kelas warna $S_{i}$ didefinisikan sebagai $\min \left\{d(v, x) \mid x \in S_{i}\right\}$. Jika $\Pi=\left\{S_{1}, S_{2}, \cdots, S_{k}\right\}$ adalah partisi terurut dari $V(G)$ berdasarkan suatu pewarnaan titik, maka kode warna dari $v$ terhadap $c$ dan partisi $\Pi$, dinotasikan $c_{\Pi}(v)$, adalah vektor- $k$ :

$$
c_{\Pi}(v)=\left(d\left(v, S_{1}\right), d\left(v, S_{2}\right), \cdots, d\left(v, S_{k}\right)\right),
$$

dimana $d\left(v, S_{i}\right)=\min \left\{d(v, x) \mid x \in S_{i}\right\}$ untuk $1 \leq i \leq k$. 
Jika setiap titik yang berbeda mempunyai kode warna yang berbeda terhadap $\Pi$, maka $c$ disebut pewarnaan lokasi (locating coloring) pada $G$. Oleh karena itu, suatu pewarnaan lokasi dari $G$ adalah pewarnaan yang membedakan setiap titik di $G$ berdasarkan jaraknya terhadap kelas warna yang dihasilkan. Bilangan kromatik lokasi (locating chromatic number) pada graf $G$ dinotasikan dengan $\chi_{L}(G)$, adalah minimum dari banyaknya warna yang digunakan pada pewarnaan lokasi di graf $G$. Karena setiap pewarnaan lokasi merupakan suatu pewarnaan, maka $\chi(G) \leq \chi_{L}(G)$ untuk setiap graf terhubung $G$.

Dalam hal ini, masih belum terlalu banyak peneliti yang mengkaji tentang bilangan kromatik lokasi dari suatu graf. Chartrand dkk. [4] yang pertama kali mengemukakan tentang konsep bilangan kromatik lokasi ini. Pada [1], telah diperoleh bilangan kromatik lokasi dari graf kembang api (firecracker) dan graf ulat, yang merupakan dua jenis graf pohon, dimana graf pohon adalah graf terhubung yang tidak memuat siklus. Pada [4] telah diketahui bahwa graf yang mempunyai $\chi_{L}(G)=1$ adalah $G \simeq K_{1}$ dan $\chi_{L}(G)=2$ adalah $G \simeq K_{2}$. Selanjutnya, Chartrand dkk [6] telah mengemukakan tentang karakterisasi semua graf berorde $n$ dengan bilangan kromatik lokasi $n, n-1$, atau $n-2$. Menarik untuk dikaji apakah terdapat graf dengan bilangan kromatik lokasi 3. Pada makalah ini dikaji kembali karakterisasi graf pohon dengan bilangan kromatik lokasi 3, seperti dibahas dalam [2].

Pada Lema 1.1 - Lema 1.3 diberikan beberapa konsep yang akan digunakan dalam pembahasan selanjutnya.

Lema 1.1. [2] Misalkan $G$ adalah graf dengan bilangan kromatik lokasi-k. Maka terdapat paling banyak $k$ titik dominan di $G$ dan semua titik dominan tersebut mempunyai warna yang berbeda.

Lema 1.2. [2] Misalkan $G$ adalah graf dengan bilangan kromatik lokasi 3. Maka sebarang lintasan clear mempunyai panjang ganjil.

Lema 1.3. [2] Misalkan $G$ graf terhubung dengan bilangan kromatik lokasi 3. Misalkan $G$ memuat 3 titik dominan. Maka ketiga titik dominan tersebut terletak dalam sebuah lintasan.

\section{Karakterisasi Graf Pohon Dengan Bilangan Kromatik Lokasi 3}

Graf pohon adalah suatu graf terhubung yang tidak memuat siklus. Selanjutnya sisi pendant didefinisikan sebagai sisi yang terkait pada titik pendant. Misal terdapat satu sisi $e=x y$. Maka subdivisi dari sisi $x y$ tersebuat didefinisikan sebagai penambahan titik-titik di antara kedua titik $x$ dan $y$.

Misalkan terdapat dua graf ulat $C(2,2,2)$ dan $C(2,1, \overbrace{0, \cdots, 0}^{t}, 1,2)$, untuk setiap $t$ ganjil. Misalkan $G_{1}$ adalah subdivisi dari $C(2,2,2)$ dengan enam sisi-sisi pendant masing-masing sebanyak $k_{1}, k_{2}, \cdots, k_{6}$ buah titik, dimana $k_{i} \geq 1$. Misalkan $G_{2}$ adalah subdivisi dari $C(2,1, \overbrace{0, \cdots, 0}^{t}, 1,2)$ pada enam sisi pendant masing-masing di $k_{1}, k_{2}, \cdots, k_{6}$, dimana $k_{i} \geq 1$. 
Misal $\mathcal{T}$ adalah kelas yang memuat semua graf pohon yang mempunyai bilangan kromatik lokasi 3. Pada bagian ini, akan dikarakterisasi semua pohon yang merupakan anggota dari $\mathcal{T}$.

Lema 2.1. [2] Misalkan $T \in \mathcal{T}$. Maka kode warna pada setiap titik di $T$ adalah $\left(c_{1}, c_{2}, c_{3}\right)$ sedemikian sehingga $\left\{c_{1}, c_{2}, c_{3}\right\}=\{0,1, k\}$ dimana $k \geq 1$.

Bukti. Misalkan $x \in V(T)$ dan tanpa menghilangkan perumuman, asumsikan $c(x)=1$. Karena tetangga dari $x$ harus mempunyai warna yang berbeda dengan $x$, maka kode warna dari $x$ adalah $(0,1, k)$ atau $(0, k, 1)$, dimana $k \geq 1$.

Lema 2.2. [2] Misalkan $T \in \mathcal{T}$. Maka setiap titik $x$ di $T$ memiliki derajat paling banyak 4 .

Bukti. Dengan kontradiksi, andaikan terdapat $a \in V(T)$ sehingga $d(a) \geq 5$. Misalkan $a_{1}, a_{2}, a_{3}, a_{4}$ dan $a_{5}$ adalah tetangga dari $a$. Asumsikan $c(a)=1$ dan $c\left(a_{i}\right)$ adalah 2 atau 3 untuk $i \in\{1,2,3,4,5\}$. Maka, salah satu dari kelas warna $\left\{S_{2}, S_{3}\right\}$ beranggotakan tiga titik. Akibatnya, dua dari tiga titik yang berada pada kelas warna yang sama akan mempunyai kode warna yang sama, suatu kontradiksi.

Berdasarkan asumsi sebelumnya, diperoleh kode warna $a_{1}, a_{3}, a_{5}$ sama dan kode warna $a_{2}, a_{4}$ sama. Jika $c\left(a_{i}\right)=2$ untuk $i \in\{1,2,3,4,5\}$, maka terdapat dua titik yang mempunyai kode warna yang sama, suatu kontradiksi. Didefinisikan $r=$ $\min \left\{d\left(a_{1}, S_{3}\right)\right\}$ untuk $i=1,2,3,4,5$, dan salah satu titik dengan warna 3 adalah titik $x$.

Berdasar pewarnaan tersebut, diperoleh kode warna dari $\left\{a, a_{1}, a_{2}, a_{3}, a_{4}, a_{5}, x\right\}$ terhadap $\Pi=\left\{S_{1}, S_{2}, S_{3}\right\}$ adalah sama. Dengan cara yang serupa, jika $c\left(a_{i}\right)=3$ untuk $i=1,2,3,4,5$, juga diperoleh dua titik dengan kode warna yang sama. Jadi, $d(a) \leq 4$

Misalkan $T \in \mathcal{T}$. Berdasarkan Lema 1.1, graf $T$ mempunyai paling banyak tiga titik dominan. Jelas, jika $T$ adalah lintasan $P_{3}$ atau $P_{4}$, bintang ganda $S_{1,2}$ atau $S_{2,2}$, maka $T$ mempunyai pewarnaan lokasi sedemikian sehingga $T$ hanya mempunyai satu atau dua titik dominan. Misalkan $x, y$ dan $z$ adalah titik-titik dominan di $T$. Asumsikan $c(x)=1, c(y)=2$ dan $c(z)=3$.

Berdasarkan Lema 1.2, terdapat dua lintasan clear yang menghubungkan $x$ ke $z$. Misalkan kedua lintasan tersebut adalah ${ }_{x} P_{y}:=\left(x=u_{0}, u_{1}, u_{2}, \cdots, u_{r-1}, u_{r}=y\right)$ dan ${ }_{y} P_{z}:=\left(y=v_{0}, v_{1}, v_{2}, \cdots, v_{s-1}, v_{s}=z\right)$ dengan $r, s$ adalah ganjil. Maka, $c\left(u_{i}\right)=1$ untuk $i$ genap dan 2 untuk $i$ ganjil; dan $c\left(v_{i}\right)=2$ untuk $i$ genap dan 3 untuk $i$ ganjil. Sebaliknya akan ada empat titik dominan di $T$. Karena $x$ adalah titik dominan di $T$, maka $d(a) \geq 2$. Akibatnya ada tetangga dari $x$ (selain $u_{1}$ ), misalkan $a$ dengan $c(a)=3$. Demikian juga, terdapat $b$, tetangga dari $z$ (selain $v_{s-1}$ ), dengan $c(b)=1$. Jadi, terdapat sebuah lintasan $P$, yaitu $P=\left(a, x, u_{1}, u_{2}, \cdots, u_{r-1}, u_{r}=y, v_{1}, v_{2}, \cdots, v_{s-1}, v_{s}=z, b\right)$, dengan $r, s$ adalah ganjil. Jika $r, s>1$ maka didefinisikan $u^{*}=u_{\left\lfloor\frac{r}{2}\right\rfloor}, u^{* *}=u_{\left\lfloor\frac{r+1}{2}\right\rfloor}, v^{*}=v_{\left\lfloor\frac{s}{2}\right\rfloor}$, $v^{* *}=v_{\left\lfloor\frac{s+1}{2}\right\rfloor}$, dimana $\lfloor x\rfloor$ adalah bilangan bulat terbesar yang lebih kecil atau sama dengan $x$. 
Lema 2.3. [2] Jika $r=s=1$, maka :

(a) $1 \leq d(a) \leq 2,2 \leq d(x) \leq 3,2 \leq d(y) \leq 4,2 \leq d(z) \leq 3$ dan $1 \leq d(b) \leq 2$.

(b) Setiap titik $w \in V(T) \backslash P$ memiliki derajat paling banyak 2 dan terhubung oleh suatu lintasan terpendek tunggal ke salah satu titik di $\{a, x, y, z, b\}$.

Bukti. Akan dibuktikan terlebih dahulu bagian (a). Dengan kontradiksi, asumsikan $d(a) \geq 3$. Maka dua tetangga dari $a$ (selain dari $x$ ), misalkan $c$ dan $d$. Jika warna $c$ dan $d$ sama, maka diperoleh bahwa kode warna keduanya sama. Jika kode warnanya berbeda, maka mengakibatkan, $d(a) \leq 2$ dan $d(b) \leq 2$. Selanjutnya, karena $x$ adalah titik dominan, maka $d(x) \geq 2$. Asumsikan $d(x) \geq 4$. Maka, dua tetangga dari $x$ akan memiliki kode warna yang sama, suatu kontradiksi. Akibatnya $2 \leq d(x) \leq 3$. Dengan cara yang sama, kita mempunyai $2 \leq d(z) \leq 3$. Karena $y$ adalah titik dominan dan dengan Lema 2.2, diperoleh $2 \leq d(y) \leq 4$.

Untuk menunjukkan $(b)$, misalkan $w \in V(T) \backslash P$. Karena $T$ adalah pohon, maka terdapat tepat satu lintasan $L$, dengan panjang $t$ yang menghubungkan $w$ ke sebuah titik pada $P$. Andaikan $d(w) \geq 3$, maka terdapat dua tetangga pada $w$ adalah $w_{1}$ dan $w_{2}$, yang tidak berada pada $L$. Karena $\chi_{L}(T)=3$ dan $x, y$ dan $z$ adalah titik dominan pada $T$ maka kode warna pada $w_{1}$ dan $w_{2}$ akan sama jika warna $w_{1}$ dan $w_{2}$ sama. Kode warna dari titik-titik pada graf tersebut adalah sebagai berikut.

$$
\begin{aligned}
& c_{\Pi}\left(w_{1}\right)=(0, t+2,1), \\
& c_{\Pi}\left(w_{2}\right)=(0, t+2,1) .
\end{aligned}
$$

Jika warna $w_{1}$ dan $w_{2}$ berbeda, maka dengan cara yang sama dengan pembuktian sebelumnya diperoleh bahwa terdapat suatu titik di $P$ yang berwarna sama dengan titik $w$, mempunyai kode warna yang sama dengan $w$. Kode warna dari titik-titik pada graf tersebut adalah sebagai berikut.

$$
\begin{aligned}
c_{\Pi}(x) & =(0,1,1), \\
c_{\Pi}(y) & =(1,0,1), \\
c_{\Pi}(z) & =(1,1,0), \\
c_{\Pi}(a) & =(1,2,0), \\
c_{\Pi}(b) & =(0,2,1), \\
c_{\Pi}(w) & =(1,0,1), \\
c_{\Pi}\left(w_{1}\right) & =(0,1,2), \\
c_{\Pi}\left(w_{2}\right) & =(2,1,0) .
\end{aligned}
$$

Diperoleh bahwa titik $y$ dan $w$ memiliki kode warna yang sama. Kontradiksi. Maka haruslah $d(w)<3$.

Lema 2.4. [2] Jika $r=1$ dan $s>1$ maka :

(a) $1 \leq d(a) \leq 2,2 \leq d(x) \leq 3,2 \leq d(y) \leq 3,2 \leq d\left(v^{*}\right) \leq 3,2 \leq d\left(v^{* *}\right) \leq 3$, $d(z)=2$, dan $1 \leq d(b) \leq 2$. Semua titik internal selain $v_{i}$ di $P$ mempunyai derajat 2 . 
(b) Setiap titik $w \in V(T) \backslash P$ mempunyai derajat paling banyak 2 dan terhubung melalui suatu lintasan tunggal ke salah satu titik di $\left\{a, x, y, b, v^{*}, v^{* *}\right\}$.

Bukti. Pembuktian dilakukan dengan cara yang sama seperti Lema 2.3.

Lema 2.5. [2] Jika, $r>1$ dan $s>1$ maka:

(a) $1 \leq d(a) \leq 2, d(x)=d(y)=d(z)=2,2 \leq d\left(u^{*}\right) \leq 3,2 \leq d\left(u^{* *}\right) \leq 3$, $2 \leq d\left(v^{*}\right) \leq 3,2 \leq d\left(v^{* *}\right) \leq 3$, dan $d(b) \leq 2$. Semua titik internal selain di $P$ mempunyai derajat 2 .

(b) Setiap titik $w \in V(T) \backslash P$ terhubung dengan lintasan tunggal untuk salah satu pada $\left\{a, b, u^{*}, u^{* *}, v^{*}, v^{* *}\right\}$.

Bukti. Pembuktian dilakukan dengan cara yang sama seperti Lema 2.3.

Pada Teorema 2.6 berikut akan ditunjukkan beberapa syarat untuk pohon yang menjadi anggota $\mathcal{T}$, seperti yang telah dibahas dalam [2].

Teorema 2.6. [2] Jika $T \in \mathcal{T}$ dan $T$ mempunyai maksimum titik yang berderajat lebih atau sama dengan 2 , maka $T$ isomorfik dengan $G_{1}$ atau $G_{2}$.

Bukti. Misalkan $T \in \mathcal{T}$. Berdasarkan Lema 1.1, $T$ memuat paling banyak tiga titik dominan. Jika $T$ adalah lintasan $P_{3}$ atau $P_{4}$, sebuah bintang ganda $S_{1,2}$ atau $S_{2,2}$, maka $T$ mempunyai pewarnaan lokasi sedemikian sehingga $T$ mempunyai satu atau dua titik dominan. Jika $T$ bukan salah satu dari keempat graf tersebut, maka $T$ akan mempunyai pewarnaan lokasi dengan tepat tiga titik dominan. Misalkan $x, y, z$ adalah titik dominan tersebut. Maka berdasar Lema 1.2, terdapat dua lintasan clear yaitu: ${ }_{x} P_{y}=\left(x=u_{0}, u_{1}, u_{2}, \cdots, u_{r-1}, u_{r}=y\right)$, ${ }_{y} P_{z}=\left(y=v_{0}, v_{1}, v_{2}, \cdots, v_{s-1}, v_{s}=z\right)$, dengan $r, s$ ganjil.

Jika $r=s=1$ maka berdasarkan Lema 2.3, $T$ mempunyai maksimum titik berderajat lebih atau sama dengan 2 , jika terdapat dua lintasan yang terkait dengan $\mathrm{y}$, dan satu lintasan terkait dengan setiap titik $a, x, z$ dan $b$. Sekarang, definisikan warna $c: V(T) \rightarrow\{1,2,3\}$ sehingga:

(1) $c(a)=3, c(x)=1, c(y)=2, c(z)=3, c(b)=1$;

(2) Warna titik pada lintasan $L_{a}$ yang terkait dengan $a$ adalah 1 dan 3 secara berselang seling;

(3) Warna titik pada lintasan $L_{x}$ yang terkait dengan $x$ adalah 2 dan 1 secara berselang seling;

(4) Warna titik pada lintasan pertama $L_{y}^{1}$ yang terkait dengan $y$ adalah 1 dan 2 secara berselang seling;

(5) Warna titik pada lintasan kedua $L_{y}^{2}$ yang terkait dengan $y$ adalah 3 dan 2 secara berselang seling;

(6) Warna titik pada lintasan $L_{z}$ yang terkait dengan $z$ adalah 2 dan 3 secara berselang seling;

(7) Warna titik pada lintasan $L_{b}$ yang terkait dengan $b$ adalah 3 dan 1 secara berselang seling. 
Kode warna pada semua titik di $L_{a}$ adalah (1, genap, 0$)$ atau (0, ganjil, 1$)$ Kode warna pada semua titik di $L_{x}$ adalah $(0,1$, ganjil) atau $(1,0$, genap). Kode warna pada semua titik di $L_{y}^{1}$ adalah $(0,1$, genap) atau $(1,0$, ganjil). Kode warna pada semua titik di $L_{y}^{2}$ adalah ( ganjil, 0,1 ) atau ( genap, 1,0 ). Kode warna pada semua titik di $L_{z}$ adalah ( genap,0,1) atau (ganjil, 1,0). Kode warna pada semua titik di $L_{b}$ adalah $(0$, ganjil, 1$)$ atau $(1$, genap, 0$)$. Oleh karena itu semua kode warna berbeda. Dengan demikian, $c$ adalah pewarnaan lokasi pada $T$. Karena 3 adalah bilangan terkecil pada warna maka $\chi_{L}(T)=3$. Pada kasus ini, $T$ isomorfik dengan $G_{1}$. Jika $r=1$ dan $s>1$ maka berdasar Lema 2.4, $T$ akan mempunyai maksimum titik dengan derajat lebih atau sama dengan 2 , jika terdapat satu lintasan terkait dengan setiap titik $a, x, y, v_{*}, v_{* *}$ dan $b$. Sekarang, definisikan warna $c: V(T) \rightarrow$ $\{1,2,3\}$ sehingga:

(1) $c(a)=3, c(x)=1, c(y)=2, c(z)=3, c(b)=1$;

(2) Warna titik pada lintasan $L_{a}$ yang terkait dengan $a$ adalah 1 dan 3 secara berselang seling;

(3) Warna titik pada lintasan $L_{x}$ yang terkait dengan $x$ adalah 2 dan 1 secara berselang seling;

(4) Warna titik pada lintasan $L_{y}$ yang terkait dengan $y$ adalah 1 dan 2 secara berselang seling;

(5) Warna titik internal $v_{i} s$ adalah 3 dan 2 secara berselang seling;

(6) Warna titik pada lintasan $L_{v^{*}}$ yang terkait dengan $v^{*}$ adalah 2 dan 3 secara berselang seling;

(7) Warna titik pada lintasan $L_{v^{* *}}$ yang terkait dengan $v^{* *}$ adalah 3 dan 2 secara berselang seling;

(8) Warna titik pada lintasan $L_{b}$ yang terkait dengan $b$ adalah 3 dan 1 secara berselang seling.

Dapat ditunjukkan bahwa kode warna pada semua titik di $T$ berbeda. Oleh karena itu, $c$ adalah pewarnaan lokasi pada $T$. Karena 3 adalah minimum dari banyaknya warna yang mungkin, maka $\chi_{L}(T)=3$. Dalam kasus ini, $T$ isomorfik dengan $G_{2}$. Jika $r>1$ dan $s>1$ maka dengan Lema 2.5, $T$ memiliki maksimum titik dengan derajat lebih atau sama dengan 2 jika terdapat satu lintasan yang terkait dengan setiap $a, x, y, v_{*}, v_{* *}$ dan $b$. Dengan mendefinisikan pewarnaan yang sama, namakan $c$ diperoleh $\chi_{L}(T)=3$. Pada kasus ini, $T$ isomorfik dengan $G_{2}$.

\section{Ucapan Terima Kasih}

Penulis mengucapkan terima kasih kepada Ibu Dr. Lyra Yulianti, Bapak Dr. Dodi Devianto, Bapak Syafruddin, M.Si dan Bapak Zulakmal, M.Si yang telah memberikan masukan dan saran sehingga artikel ini dapat diselesaikan dengan baik.

\section{Daftar Pustaka}

[1] Asmiati. 2012. Bilangan Kromatik Lokasi Graf Pohon dan Karakterisasi Graf dengan Bilangan Kromatik Lokasi 3, Disertasi, tidak diterbitkan, Institut Teknologi Bandung. 
[2] Baskoro E. T dan Asmiati. 2013. Characterizing all trees with locatingchromatic number 3. Electronic Journal of Graph Theory and Applications 2: $109-117$.

[3] Bondy J. A. dan U.S.R Murty. 1976. Graph Theory with Applications. London.

[4] Chartrand G, D. Erwin, M.A. Henning, P.J. Slater, P. Zhang. 2002. The Locating-Chromatics Number of a Graph, Bull. Inst. Combin. April. 36 : 89 $-101$.

[5] Chartrand G., D. Erwin, M.A. Henning, P.J. Slater, P. Zhang. 2003. Graph of Order n With Locating-Chromatic Number n-1, Discrete Math. 269 (1-3) : 65 -79 .

[6] Chartrand G. and P. Zhang. 2003. The Theory and Application of Resolvability in Graph, Congressus Numerantium 160 : $47-68$. 